\title{
Approximating the DGP of China's Quarterly GDP
}

\author{
Philip Hans Franses \\ Heleen Mees \\ Econometric Institute \\ Erasmus School of Economics
}

Econometric Institute Report EI-2010-04

\begin{abstract}
We demonstrate that the data generating process (DGP) of China's cumulated quarterly Gross Domestic Product (GDP, current prices), as it is reported by the National Bureau of Statistics of China, can be (very closely) approximated by a simple rule. This rule is that annual growth in any quarter is equal to annual growth in its previous quarter plus an error term that is only nonzero in the first quarter of each year and with small variance. We show that this rule fits the data for 1992Q1 to 2005Q4 well, for total GDP as well for its three sector-specific components. It also gives accurate forecasts for 2006Q1 to 2009Q4. We also study the time series properties of GDP growth in constant prices, and show that these series behave as random walks, with much larger error variance.
\end{abstract}

This version: February 42010

Authors' notes: Thanks are due to Dick van Dijk and Michael McAleer for helpful discussions. Address for correspondence is Econometric Institute, Erasmus University Rotterdam, PO Box 1738, NL-3000 DR, Rotterdam, franses@ese.eur.nl 


\section{Introduction}

Since 1992 China presents its quarterly GDP figures in a format that is accessible to the general public. In 2007 the National Bureau of Statistics of China (NBSC) published the China Quarterly GDP Time Series for 1992Q1-2005Q4. Since 2006 this information also appears on the NBSC website (www.stats.gov.cn).

In this paper we analyze the time series properties of the GDP series as they are given as aggregates in current prices (100 million Yuan). We will analyze the total GDP series as well as the three sector-specific GDP series, concerning the Primary, Secondary and Tertiary Sectors. We construct time series models for the data covering 1992Q12005Q4, and we use these models to forecast the data for 2006Q1 to 2009Q4. The data are presented in Appendix A and B. We also analyze the GDP growth rates at constant prices, and these data appear in Appendix C and D.

The Chinese GDP series in current prices are reported in a format that contrasts with the usual practice in western countries. First, the data are given in cumulated format, that is, Quarter 1 first, and then in Quarter 2 the NBSC presents the sum of Quarters 1 and 2, and so on. Second, when cumulating the data, NBSC also includes revised figures of earlier quarters. Third, after one year, it is only the cumulated value in Quarter 4 (which is of course equal to the sum for that particular year) that is revised. ${ }^{12}$ To write it in a more formal way, denote actual, that is, de-cumulated GDP in a single year as $Y_{Q, T}$, where Q is either Quarter 1, 2, 3 or 4, and T is year. Next, denote $Y_{Q, T}^{r}$ as the first revised value of the quarter, $Y_{Q, T}^{r r}$ as the second revised value, and so on. The data that the NBSC subsequently reports in the Quarters 1 to 4 are thus equal to

\footnotetext{
${ }^{1}$ The practice of presenting cumulated data is a heritage of the planned economy, where macroeconomic data are expected to meet certain targets. By using cumulated data, one can see at a glance to what extent the targets have been met.

${ }^{2}$ Since 2003 the NBSC is reporting de-cumulated growth figures in its press releases, but not in the time series on the NSBC website.
} 


$$
\begin{aligned}
& X_{1, T}=Y_{1, T} \\
& X_{2, T}=Y_{1, r T}^{r}+Y_{2, T} \\
& X_{3, T}=Y_{1, T}^{r r}+Y_{2, T}^{r}+Y_{3, T} \\
& X_{4, T}=Y_{1, T}^{r r r}+Y_{2, T}^{r r}+Y_{3, T}^{r}+Y_{4, T}
\end{aligned}
$$

And, with (approximately) a one year lag, NBSC presents $X_{4, T}^{r}$, the revised year-total. A consequence of this way of reporting is that the data have graphical patterns like those reported in Figures 1 and 2. Another consequence is for de-cumulated GDP for China, which would amount to data like $X_{2, T}-X_{1, T}$, and so on, and that is that these data are difficult to interpret and to analyze as they amount to a mixture of actual figures and revisions. In fact, the actual and revised figures can simply not be identified. A graph of the de-cumulated data which we will not analyze in this paper appears in the Appendix. A third consequence is that a random error term in Quarter 1 will have largest variance, as the forecast errors for subsequent quarters must get smaller due to the accumulation as in (1).

In this paper we focus on the actual data as presented by the NBSC, that is, those as constructed in (1), the cumulated GDP data at current prices. Additionally, we analyze the time series properties of real growth rates (concerning cumulated GDP at constant prices).

Our rather basic analysis shows that the GDP data (cumulated levels at current prices) can be fitted and predicted with (relatively) great precision. The rule that seems to govern the data is that growth in a quarter, relative to the same quarter in the previous year, is a random walk. Second, as expected, this random walk experiences shocks only in the first quarter, and in the other three quarters, the error term has variance (approximately) equal to zero. In words this means that once the observation in Quarter 1 is known, the data for the rest of the year can be predicted quite accurately. We show that the median percentage error of one-step-ahead forecasts for the actual nominal GDP (in 100 million Yuan) for these quarters has a mean often lower than $1.0 \%$. In terms of decumulated series, such a forecast precision is associated with a de-cumulated series with a very regular seasonal pattern, with a steep trend, and with no important downturns. 
GDP growth in constant prices can also be described as a random walk, albeit that the error term variance is much larger. As a result, real GDP growth, as opposed to nominal GDP growth, cannot accurately be predicted through extrapolation.

\section{An analysis of cumulative GDP in current prices}

We start with an analysis of cumulative total GDP, as it is given in Figure 1, for the sample 1992Q1 to 2005Q4. The data seem to have a trend (upwards) and strong and increasing seasonality, which is of course largely due to the accumulation process. It is common in such instances to take logarithms of the data and to use so-called differencing filters to remove non-stationary components, see Franses (1998), among others. Denoting the quarterly series as composed like (1) as $x_{t}$, where $t$ runs from 1992Q1 to 2005Q4, then we shall analyze the properties of

$$
(1-L)\left(1-L^{4}\right) \log x_{t}
$$

The $L$ denotes the familiar lag operator and "log" denotes the natural logarithm. In words, the variable in (2) is the change (1-L) in the annual growth rate $\left(1-L^{4}\right) \log x_{t}$, observed per quarter. A graph of the series in (2) is given in Figure 3.

\subsection{Approximating the DGP}

The time series properties of this variable turn out to have interesting properties, and certainly when compared with GDP data for other countries. The first property is that the mean of the variable in Figure 3 is equal to zero. A regression of $(1-L)\left(1-L^{4}\right) \log x_{t}$ on a constant gives a t-ratio of -0.990 . The residuals of this regression do not appear to be auto-correlated. The LM test for first to fourth auto-correlation has a p-value of 0.164. This is quite interesting as many quarterly and trending economic time series can be 
described by the so-called airline model ${ }^{3}$, which implies auto-correlations for $(1-L)\left(1-L^{4}\right) \log x_{t}$ at lags $1,3,4$ and 5 .

The series $(1-L)\left(1-L^{4}\right) \log x_{t}$ has a second interesting property and that is that in the regression of the squares of $(1-L)\left(1-L^{4}\right) \log x_{t}$ on four seasonal dummies only the parameter for the first seasonal dummy obtains a significant parameter (t-statistic is 6.977). Basically this means that total GDP in current prices can be described by

$$
(1-L)\left(1-L^{4}\right) \log x_{t} \sim\left(0, D_{1, t} \sigma^{2}\right)
$$

where $D_{1, t}$ is a one-zero seasonal dummy for the first quarter and $\sigma^{2}$ is the variance of the error term. The variance is estimated as 0.001098 with standard error 0.000151 . The finding that only the variance in the first quarter matters is largely due to the accumulation process. On the other hand, that the variance is very small implies that the associated de-cumulated series would show a very regular and repetitive seasonal pattern, a steep and straight trend, and an absence of important downturns.

\subsection{Forecasts}

The expression in (3) says that in all quarters but the first one, the data on GDP in current prices obey the rule: growth in this quarter is equal to growth in the previous quarter. And in the first quarter, the rule is this quarter's growth is growth in the previous quarter plus a non-zero error term. In other words, the actual data $(1-L)\left(1-L^{4}\right) \log x_{t}$ are all approximately zero except in Quarter 1, which is visualized in Figure 4.

With the model in (3), we can easily create forecasts for GDP, using the following extrapolation scheme:

\footnotetext{
${ }^{3}$ The airline model is given by $(1-L)\left(1-L^{4}\right) \log x_{t}=\left(1+\theta_{1} L\right)\left(1+\theta_{4} L^{4}\right) \varepsilon_{t}$, see Franses (1998, Chapter 5), where $\varepsilon_{t}$ is an error term with zero auto-correlation. This model is also at the heart of various seasonal adjustment programs.
} 


$$
G D P_{t+h}=\exp \left[\log \left(G D P_{t+h-1}\right)+\log \left(G D P_{t+h-4}\right)-\log \left(G D P_{t+h-5}\right)+\frac{1}{2} D_{1, t+h} \sigma^{2}\right]
$$

where $G D P_{t+h}$ denotes the h-step-ahead forecast. In case of recurrent one-step-ahead (static) forecasts, the forecast origin each time moves with one quarter. In case of multiple-step-ahead (dynamic) forecasts, the forecast origin is the same (2005Q4), and in (4) earlier forecasts then replace the future observations.

In Figure 5 we give the multiple-step-ahead forecasts generated from 2005Q4 as the forecast horizon, and the realizations as they are displayed in Appendix B. It is clear from this graph that these multiple-step-ahead forecasts seem to give an adequate impression of the upward trend in China's GDP. The actual forecasts are presented in Table 1. This table also gives the percentage forecast error. Even though the forecasts are created for years ahead, still the percentage forecast error remains below around $10 \%$.

In Figure 6 we give the one-step-ahead forecasts, where the first forecast origin is 2005Q4, then in becomes 2006Q1 and so on, until 2009Q3. Table 2 presents these forecasts and the percentage forecast errors. As could be expected given (3), the forecast errors in the first quarters are largest, with the exceptionally large value in 2009Q1. So, indeed, it is not easy to forecast first-quarter GDP in current prices in China. In contrast, the forecast errors for the other three quarters are small, as one can safely state that percentage forecast errors below $1 \%$ are quite small (for levels of GDP type data). The median error is 0.436 and the median absolute error is 0.599 .

The model in (3) suggests that once the first-quarter observation is known, it shall not be too difficult to forecast Quarters 2, 3 and 4. If we thus generate three-step-ahead forecasts for the final quarter (= year) GDP data, we get forecasts of 210236.0 for 2006Q4, 253135.1 for 2007Q4, 307823.5 for 2008Q4 and 311422.6 for 2009Q4. These forecasts have percentage errors equal to 0.802, 1.648, 2.021 and 7.684, respectively, which is rather small (as compared forecasts for the levels of GDP for other countries). 


\section{The three components of cumulated GDP in current prices}

Given that total cumulated GDP can be approximated by a simple model as given in (3), it is now of interest whether this also holds for its three components. Following the same approach as in the previous section, it so turns out the nominal GDP for the Primary Sector, for the Secondary Sector and for the Tertiary Sector each can be described by a model like (3), where the $\sigma^{2}$ is estimated (with standard errors in parentheses) as 0.004161 (0.000989), 0.001470 (0.000255) and 0.001341 (0.000333), respectively. Clearly, the error term has largest variance for the Primary Sector. Graphs similar to that in Figure 4 are given in Figures 7, 8 and 9. One can see a very close fit between the data and the model. Hence, the data generating process (DGP) of Chinese GDP in current prices can be approximated rather well.

In Tables 3 to 8 we present the multiple-step-ahead forecasts and one-step-ahead forecasts for the three sectors, and we contrast these with the realizations displayed in Appendix B. One can see that these forecasts are again quite accurate, although forecasts for the Secondary Sector seem to be best, except for 2009Q4.

\section{An analysis of growth rates at constant prices}

The second important variable that is reported by the National Bureau of Statistics of China is the Growth Rate of Gross Domestic Product at Constant Prices. Dong (2006) discusses the creation of these inflation-corrected growth rates. In contrast to what is common practice in western countries, NBSC does not report a single GDP deflator. In fact, each component of the national accounts has its own deflator. We might therefore expect that modeling and forecasting of this variable would be less easy than in the earlier case of cumulated GDP at current prices.

The relevant growth rates for total GDP appear in Figure 10 and for the three sectors in Figure 11. In Figure 12 we contrast the growth rates with those of the USA, where one should bear in mind that the Chinese data refer to real growth rates of cumulated data within each calendar year. Until 2007Q4, the USA growth figures show 
stability with an average of 3.2\%. The Chinese data show much more fluctuations. The data as used in this paper are displayed in Appendix C and D. Again, we analyze the data for 1992Q1 to 2005Q4 and we create forecasts for 2006Q1 to 2009Q4.

Given the fact that constant prices GDP cannot be derived as a function of current prices GDP and a GDP deflator, we shall not expect that (3) has predictive value for the models for constant prices GDP. The autocorrelations of the growth rates (total and for the three sectors) show a pattern that is typical for a unit root process (relevant more formal tests confirm this), so we will analyze the growth rates after first differencing, that is, this quarter's growth minus growth in the previous quarter.

For constant prices growth in total GDP we obtain

$$
\text { Growth }_{t}-\text { Growth }_{t-1}=0.254 D_{1, t}-0.371 D_{2, t}+\varepsilon_{t}
$$

where $D_{1, t}$ and $D_{2, t}$ are the one-zero dummies for Quarters 1 and 2. If we regress the squares of the estimated residuals on the four seasonal dummies, one can learn that the variance in Quarter 1 is about 0.97 and significant, while the variances in the other three quarters are estimated as being insignificantly different from zero. Note that this variance is substantially larger than that for nominal GDP. Anyway, similar to GDP at current prices, it shall thus be most difficult to forecast data in Quarter 1. This is reflected by the one-step-ahead forecasts in Table 9, where indeed the forecast errors are largest in the first quarter, and notably in 2008Q1 and 2009Q1.

A similar model as in (5) is obtained for the growth rates at constant prices for GDP in the Primary Sector. The estimation results are

$$
\text { Growth1 }_{t}-\text { Growth1 }_{t-1}=0.669 D_{1, t}-1.021 D_{2, t}+\varepsilon_{t}
$$

And also here we obtain that error variance in Quarter 1 is the only significant variance, with value 0.867 .

For the Secondary Sector GDP growth rates we get 


$$
\text { Growth }_{t}-\text { Growth }_{t-1}=-0.869 D_{1, t}+\varepsilon_{t}
$$

Here the error variance in Quarter 1 is 3.339, so one may expect large forecast errors in Quarter 1.

Finally, for the Tertiary Sector we obtain that the growth simply is a zero-mean random walk. The variance of this variable is 1.852 in Quarter 1 and 0.824 in Quarter 4, and otherwise this variance is zero.

In contrast with the GDP data at current prices, the GDP data at constant prices will be much less easy to forecast. This is also reflected by the forecast errors in Tables 10, 11 and 12. In particular, the forecast for 2009Q4 for the Secondary sector is quite off track.

\section{Discussion and conclusion}

In this paper we have demonstrated that quarterly Chinese GDP time series data, at current prices, can be predicted quite well using very simple extrapolation schemes. The relevance of this extrapolation scheme is in part due to the accumulation process. This forecast accuracy does not only hold for one-step-ahead forecasts, where percentage errors of less than $1 \%$ are often found, but also for multiple-step-ahead forecasts where percentage errors are much larger, but still much smaller than what is typically found for other country-specific GDP data. When econometric models are to be developed to predict GDP for China, they should have the challenge of improving this reported forecast accuracy.

In contrast to what is common practice, China does not use a single GDP deflator, but uses various different prices data to correct the current prices GDP to constant prices GDP. This should make the growth rates in constant prices GDP much less easy to model and forecast, which we verified in the second part of the paper. Basically, these growth rates are random walks, with some mild seasonality and with large variance.

Current prices GDP in China is reported in cumulated form. This makes the Quarter 4 observation automatically equal to the year total. The cumulated data contain actual quarterly data and the revisions to earlier quarters. This makes the de-cumulated 
GDP data less useful as it cannot be identified which part of the de-cumulated observation can be associated with genuine new information and with revisions. This should reduce the usefulness of de-cumulated GDP in econometric models for other macro-economic variables. At the same time, as there is almost no variation in the cumulated GDP data, at least not in Quarters 2, 3 and 4, this particular series is also less useful for subsequent econometric modeling. The only variable that could be considered for modeling and forecasting is the growth rate of GDP at constant prices.

When it comes to forecasting GDP at current prices, the only observation that seems of interest to forecast is the first-quarter observation. Given knowledge of that quarter, the next three quarters within the same year can be predicted with great accuracy.

Finally, GDP growth in constant prices can also be described as a random walk, albeit that the error term variance is much larger. Therefore real GDP growth cannot accurately be predicted through extrapolation. 


\section{Appendix A: The data for 1992Q1-2005Q4}

Aggregates in current prices, in 100 million Yuan

\begin{tabular}{|c|c|c|c|c|}
\hline Quarter & GDP & $\begin{array}{l}\text { Primary } \\
\text { Industry }\end{array}$ & $\begin{array}{l}\text { Secondary } \\
\text { Industry }\end{array}$ & $\begin{array}{l}\text { Tertiary } \\
\text { Industry }\end{array}$ \\
\hline 1992Q1 & 4974.300 & 589.9000 & 2365.200 & 2019.200 \\
\hline 1992Q2 & 11332.10 & 1690.900 & 5350.300 & 4290.900 \\
\hline 1992Q3 & 18451.50 & 3670.800 & 8319.500 & 6461.200 \\
\hline 1992Q4 & 26923.50 & 5866.600 & 11699.50 & 9357.400 \\
\hline 1993Q1 & 6500.500 & 673.1000 & 3363.800 & 2463.600 \\
\hline 1993Q2 & 14543.50 & 1897.400 & 7532.200 & 5113.900 \\
\hline 1993Q3 & 23591.50 & 4020.500 & 11574.60 & 7996.400 \\
\hline 1993Q4 & 35333.90 & 6963.800 & 16454.40 & 11915.70 \\
\hline 1994Q1 & 9064.700 & 922.7000 & 4710.100 & 3431.900 \\
\hline 1994Q2 & 20149.70 & 2539.500 & 10546.10 & 7064.100 \\
\hline 1994Q3 & 32596.60 & 5380.300 & 16248.60 & 10967.70 \\
\hline 1994Q4 & 48197.90 & 9572.700 & 22445.40 & 16179.80 \\
\hline 1995Q1 & 11858.50 & 1232.600 & 6227.100 & 4398.800 \\
\hline 1995Q2 & 25967.60 & 3420.800 & 13693.40 & 8853.400 \\
\hline 1995Q3 & 41502.60 & 7139.200 & 20775.60 & 13587.80 \\
\hline 1995Q4 & 60793.70 & 12135.80 & 28679.50 & 19978.40 \\
\hline 1996Q1 & 14261.20 & 1487.200 & 7576.500 & 5197.500 \\
\hline 1996Q2 & 30861.80 & 4251.900 & 16197.90 & 10412.00 \\
\hline 1996Q3 & 48533.10 & 8194.100 & 24413.80 & 15925.20 \\
\hline 1996Q4 & 71176.60 & 14015.40 & 33835.00 & 23326.20 \\
\hline 1997Q1 & 16256.70 & 1675.500 & 8433.500 & 6147.700 \\
\hline 1997Q2 & 34954.30 & 4730.500 & 18109.30 & 12114.50 \\
\hline 1997Q3 & 54102.40 & 8547.500 & 27084.20 & 18470.70 \\
\hline 1997Q4 & 78973.00 & 14441.90 & 37543.00 & 26988.10 \\
\hline 1998Q1 & 17501.30 & 1775.200 & 8757.100 & 6969.000 \\
\hline 1998Q2 & 37222.70 & 4860.400 & 18693.10 & 13669.20 \\
\hline 1998Q3 & 57595.20 & 8740.200 & 28013.00 & 20842.00 \\
\hline 1998Q4 & 84402.30 & 14817.60 & 39004.20 & 30580.50 \\
\hline 1999Q1 & 18789.70 & 1878.600 & 9204.800 & 7706.300 \\
\hline 1999Q2 & 39554.90 & 5039.900 & 19479.00 & 15036.00 \\
\hline 1999Q3 & 61414.20 & 9048.700 & 29436.90 & 22928.60 \\
\hline 1999Q4 & 89677.10 & 14770.00 & 41033.60 & 33873.50 \\
\hline 2000Q1 & 20647.00 & 1924.900 & 9981.400 & 8740.700 \\
\hline 2000Q2 & 43748.20 & 5094.500 & 21429.90 & 17223.80 \\
\hline 2000Q3 & 68087.50 & 9169.300 & 32629.50 & 26288.70 \\
\hline 2000Q4 & 99214.60 & 14944.70 & 45555.90 & 38714.00 \\
\hline 2001Q1 & 23299.50 & 2035.200 & 11127.40 & 10136.90 \\
\hline 2001Q2 & 48950.90 & 5297.100 & 23813.30 & 19840.50 \\
\hline 2001Q3 & 75818.20 & 9715.200 & 35856.10 & 30246.90 \\
\hline 2001Q4 & 109655.2 & 15781.30 & 49512.30 & 44361.60 \\
\hline
\end{tabular}




$\begin{array}{lllll}\text { 2002Q1 } & 25375.70 & 2181.300 & 11811.30 & 11383.10 \\ \text { 2002Q2 } & 53341.00 & 5635.200 & 25562.60 & 22143.20 \\ \text { 2002Q3 } & 83056.70 & 10325.60 & 38807.30 & 33923.80 \\ \text { 2002Q4 } & 120332.7 & 16537.00 & 53896.80 & 49898.90 \\ \text { 2003Q1 } & 28861.80 & 2258.100 & 13776.40 & 12827.30 \\ \text { 2003Q2 } & 59868.90 & 5779.400 & 29478.00 & 24611.50 \\ \text { 2003Q3 } & 93329.30 & 10866.40 & 44853.10 & 37609.80 \\ \text { 2003Q4 } & 135822.8 & 17381.70 & 62436.30 & 56004.80 \\ \text { 2004Q1 } & 33420.60 & 2663.500 & 16077.30 & 14679.80 \\ \text { 2004Q2 } & 70405.90 & 7027.500 & 34674.50 & 28703.90 \\ \text { 2004Q3 } & 109967.6 & 13385.00 & 52869.60 & 43713.00 \\ \text { 2004Q4 } & 159878.3 & 21412.70 & 73904.30 & 64561.30 \\ \text { 2005Q1 } & 38848.60 & 3013.600 & 18968.40 & 16866.60 \\ \text { 2005Q2 } & 81422.50 & 7652.000 & 40902.60 & 32867.90 \\ \text { 2005Q3 } & 125984.9 & 14451.20 & 61542.40 & 49991.30 \\ \text { 2005Q4 } & 183867.9 & 23070.40 & 87364.60 & 73432.90\end{array}$

Source: National Bureau of Statistics of China (2007), China Quarterly GDP Time Series, 1992-2005, Department of National Accounts, China Statistics Press, ISBN 978-7-50375356-5. 
Appendix B: The data for 2006Q1-2009Q4

$\begin{array}{lrrrr}\text { Quarter } & \text { GDP } & \begin{array}{c}\text { Primary } \\ \text { Industry }\end{array} & \begin{array}{r}\text { Secondary } \\ \text { Industry }\end{array} & \begin{array}{c}\text { Tertiary } \\ \text { Industry }\end{array} \\ \text { 2006Q1 } & 44419.80 & 3093.000 & 22076.10 & 19250.70 \\ \text { 2006Q2 } & 93611.60 & 7973.600 & 47909.40 & 37728.60 \\ \text { 2006Q3 } & 144569.6 & 15058.20 & 72008.20 & 57503.20 \\ \text { 2006Q4 } & 211923.0 & 24040.00 & 103162.0 & 84721.00 \\ \text { 2007Q1 } & 53058.00 & 3654.000 & 26465.00 & 22939.00 \\ \text { 2007Q2 } & 112458.0 & 9283.000 & 57614.00 & 45561.00 \\ \text { 2007Q3 } & 174428.0 & 17937.00 & 86405.00 & 70086.00 \\ \text { 2007Q4 } & 257306.0 & 28627.00 & 124799.0 & 103880.0 \\ \text { 2008Q1 } & 63475.00 & 4720.000 & 31658.00 & 27097.00 \\ \text { 2008Q2 } & 134726.0 & 11800.00 & 69330.00 & 53596.00 \\ \text { 2008Q3 } & 208025.0 & 22062.00 & 103974.0 & 81989.00 \\ \text { 2008Q4 } & 314045.0 & 33702.00 & 149003.0 & 131340.0 \\ \text { 2009Q1 } & 65745.00 & 4700.000 & 31968.00 & 29077.00 \\ \text { 2009Q2 } & 139862.0 & 12025.00 & 70070.00 & 57767.00 \\ \text { 2009Q3 } & 217817.0 & 22500.00 & 106477.0 & 88840.00 \\ \text { 2009Q4 } & 335353.0 & 35477.00 & 156958.0 & 142918.0\end{array}$

Source: http://www.stats.gov.cn/english (Consulted: January 22 2010) 


\section{DECUMULATED_GDP}

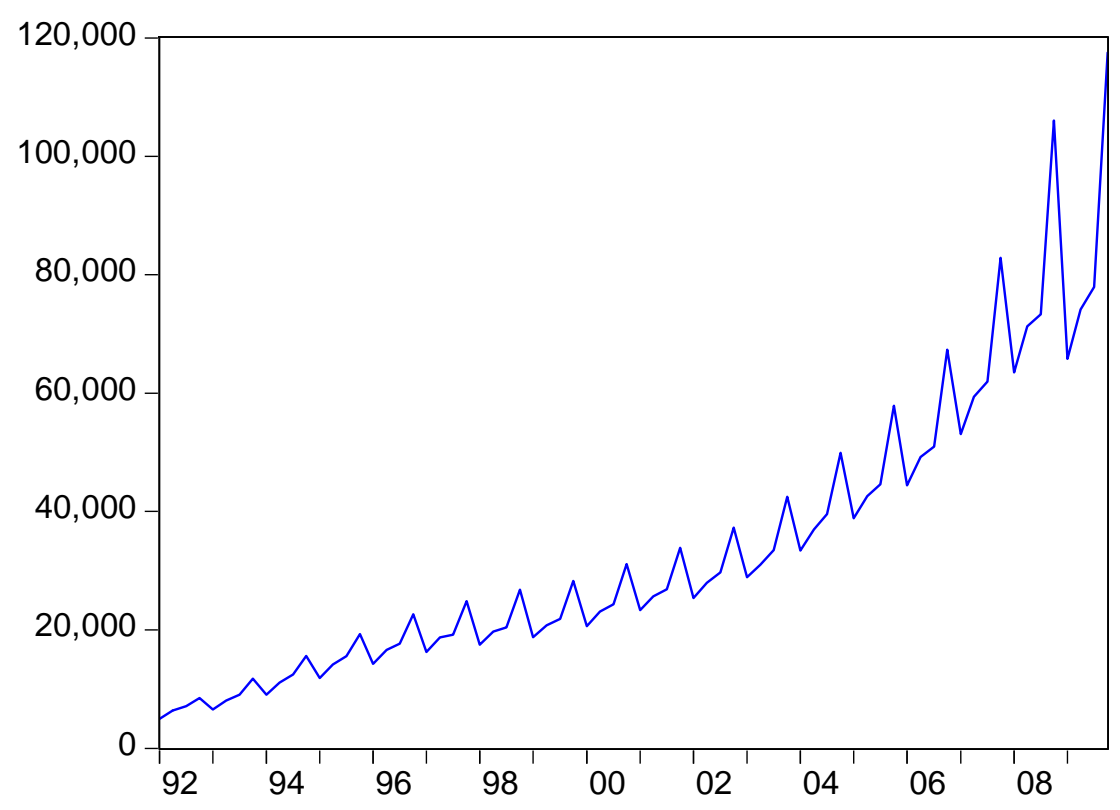

Figure A1: Quarterly GDP (de-cumulated) as the aggregate in current prices, 1992Q12009Q4 


\section{Appendix C: The data for 1992Q1-2005Q4}

The data in this table are calculated at constant prices, and are relative to the same period of the preceding year $=100$

\begin{tabular}{|c|c|c|c|c|}
\hline Quarter & GROWTH & GROWTH1 & GROWTH2 & GROWTH3 \\
\hline 1992Q1 & 13.6 & 10.0 & 17.4 & 9.80 \\
\hline 1992Q2 & 13.3 & 7.70 & 18.0 & 9.50 \\
\hline 1992Q3 & 13.3 & 5.50 & 18.8 & 10.8 \\
\hline 1992Q4 & 14.2 & 4.70 & 21.2 & 12.4 \\
\hline 1993Q1 & 15.1 & 6.10 & 19.4 & 12.2 \\
\hline 1993Q2 & 14.8 & 4.20 & 19.7 & 13.1 \\
\hline 1993Q3 & 14.3 & 4.20 & 19.4 & 13.0 \\
\hline 1993Q4 & 14.0 & 4.70 & 19.9 & 12.2 \\
\hline 1994Q1 & 12.9 & 6.00 & 16.5 & 9.80 \\
\hline 1994Q2 & 12.4 & 4.50 & 16.6 & 9.60 \\
\hline 1994Q3 & 12.4 & 4.50 & 16.9 & 9.90 \\
\hline 1994Q4 & 13.1 & 4.00 & 18.4 & 11.1 \\
\hline 1995Q1 & 12.0 & 6.00 & 14.7 & 9.70 \\
\hline 1995Q2 & 11.0 & 6.20 & 13.6 & 8.80 \\
\hline 1995Q3 & 10.6 & 5.50 & 13.1 & 9.20 \\
\hline 1995Q4 & 10.9 & 5.00 & 13.9 & 9.80 \\
\hline 1996Q1 & 10.9 & 5.50 & 12.3 & 10.2 \\
\hline 1996Q2 & 10.3 & 5.00 & 12.0 & 9.60 \\
\hline 1996Q3 & 10.0 & 4.80 & 11.9 & 9.60 \\
\hline 1996Q4 & 10.0 & 5.10 & 12.1 & 9.40 \\
\hline 1997Q1 & 10.4 & 5.00 & 10.3 & 12.2 \\
\hline 1997Q2 & 10.2 & 5.00 & 10.7 & 11.6 \\
\hline 1997Q3 & 9.60 & 3.90 & 10.3 & 11.5 \\
\hline 1997Q4 & 9.30 & 3.50 & 10.5 & 10.7 \\
\hline 1998Q1 & 7.60 & 4.00 & 7.60 & 8.60 \\
\hline 1998Q2 & 7.20 & 2.20 & 7.70 & 8.50 \\
\hline 1998Q3 & 7.50 & 2.50 & 8.10 & 9.00 \\
\hline 1998Q4 & 7.80 & 3.50 & 8.90 & 8.40 \\
\hline 1999Q1 & 9.10 & 4.00 & 9.60 & 9.50 \\
\hline 1999Q2 & 8.30 & 3.00 & 9.00 & 9.20 \\
\hline 1999Q3 & 8.10 & 3.30 & 8.70 & 9.30 \\
\hline 1999Q4 & 7.60 & 2.80 & 8.10 & 9.30 \\
\hline 2000Q1 & 9.00 & 3.00 & 9.10 & 10.4 \\
\hline 2000Q2 & 8.90 & 1.50 & 9.50 & 10.7 \\
\hline 2000Q3 & 8.90 & 2.20 & 9.60 & 10.7 \\
\hline 2000Q4 & 8.40 & 2.40 & 9.40 & 9.70 \\
\hline 2001Q1 & 8.50 & 3.10 & 9.20 & 8.80 \\
\hline 2001Q2 & 8.10 & 1.80 & 9.50 & 8.40 \\
\hline 2001Q3 & 8.00 & 2.90 & 9.10 & 8.40 \\
\hline 2001Q4 & 8.30 & 2.80 & 8.40 & 10.3 \\
\hline 2002Q1 & 8.90 & 3.40 & 9.10 & 9.90 \\
\hline 2002Q2 & 8.90 & 2.00 & 9.50 & 10.1 \\
\hline
\end{tabular}




$\begin{array}{lllll}\text { 2002Q3 } & 9.20 & 3.40 & 9.80 & 10.2 \\ \text { 2002Q4 } & 9.10 & 2.90 & 9.80 & 10.4 \\ \text { 2003Q1 } & 10.8 & 3.60 & 12.5 & 10.3 \\ \text { 2003Q2 } & 9.70 & 2.10 & 11.8 & 9.10 \\ \text { 2003Q3 } & 10.1 & 3.10 & 12.5 & 9.30 \\ \text { 2003Q4 } & 10.0 & 2.50 & 12.7 & 9.50 \\ \text { 2004Q1 } & 10.4 & 4.60 & 11.6 & 10.0 \\ \text { 2004Q2 } & 10.9 & 4.40 & 11.5 & 11.6 \\ \text { 2004Q3 } & 10.5 & 6.00 & 11.1 & 10.9 \\ \text { 2004Q4 } & 10.1 & 6.30 & 11.1 & 10.1 \\ \text { 2005Q1 } & 10.5 & 4.60 & 11.2 & 10.6 \\ \text { 2005Q2 } & 10.5 & 5.00 & 11.3 & 10.8 \\ \text { 2005Q3 } & 10.4 & 5.00 & 11.2 & 10.9 \\ \text { 2005Q4 } & 10.4 & 5.20 & 11.7 & 10.5\end{array}$




\section{Appendix D: The data for 2006Q1-2009Q4}

The data in this table are calculated at constant prices, and are relative to the same period of the preceding year $=100$

$\begin{array}{rrrrr}\text { Quarter } & \text { GROWTH } & \text { GROWTH1 } & \text { GROWTH2 } & \text { GROWTH3 } \\ \text { 2006Q1 } & 11.4 & 4.50 & 12.6 & 11.3 \\ \text { 2006Q2 } & 12.0 & 5.10 & 13.6 & 11.7 \\ \text { 2006Q3 } & 11.8 & 4.90 & 13.3 & 11.8 \\ \text { 2006Q4 } & 11.6 & 5.00 & 13.0 & 12.1 \\ \text { 2007Q1 } & 13.0 & 4.40 & 14.6 & 12.7 \\ \text { 2007Q2 } & 13.4 & 4.00 & 15.0 & 13.5 \\ 2007 Q 3 & 13.4 & 4.30 & 14.8 & 14.0 \\ 2007 Q 4 & 13.0 & 3.70 & 14.7 & 13.8 \\ 2008 Q 1 & 10.6 & 2.80 & 11.5 & 10.9 \\ 2008 Q 2 & 10.4 & 3.50 & 11.3 & 10.7 \\ 2008 Q 3 & 9.90 & 4.50 & 10.6 & 10.5 \\ 2008 Q 4 & 9.00 & 5.50 & 9.30 & 9.50 \\ 2009 Q 1 & 6.10 & 3.50 & 5.30 & 7.40 \\ 2009 Q 2 & 7.10 & 3.80 & 6.60 & 8.30 \\ 2009 Q 3 & 7.70 & 4.00 & 7.50 & 8.80 \\ 2009 Q 4 & 8.70 & 4.20 & 9.50 & 8.90\end{array}$

Source: http://www.stats.gov.cn/english (Consulted: January 22 2010) 


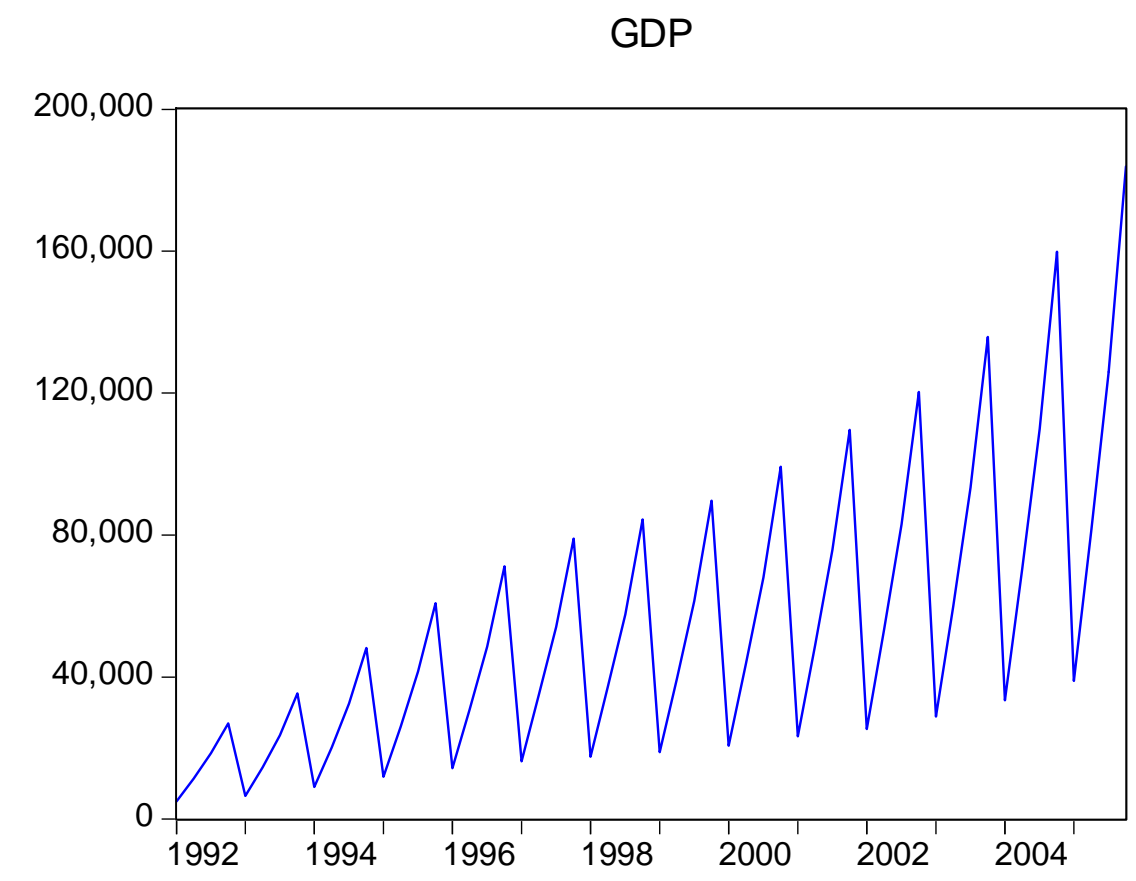

Figure 1: Quarterly GDP (cumulated) as the aggregate in current prices, 1992Q1-2005Q4 (the data are given in Appendix A) 


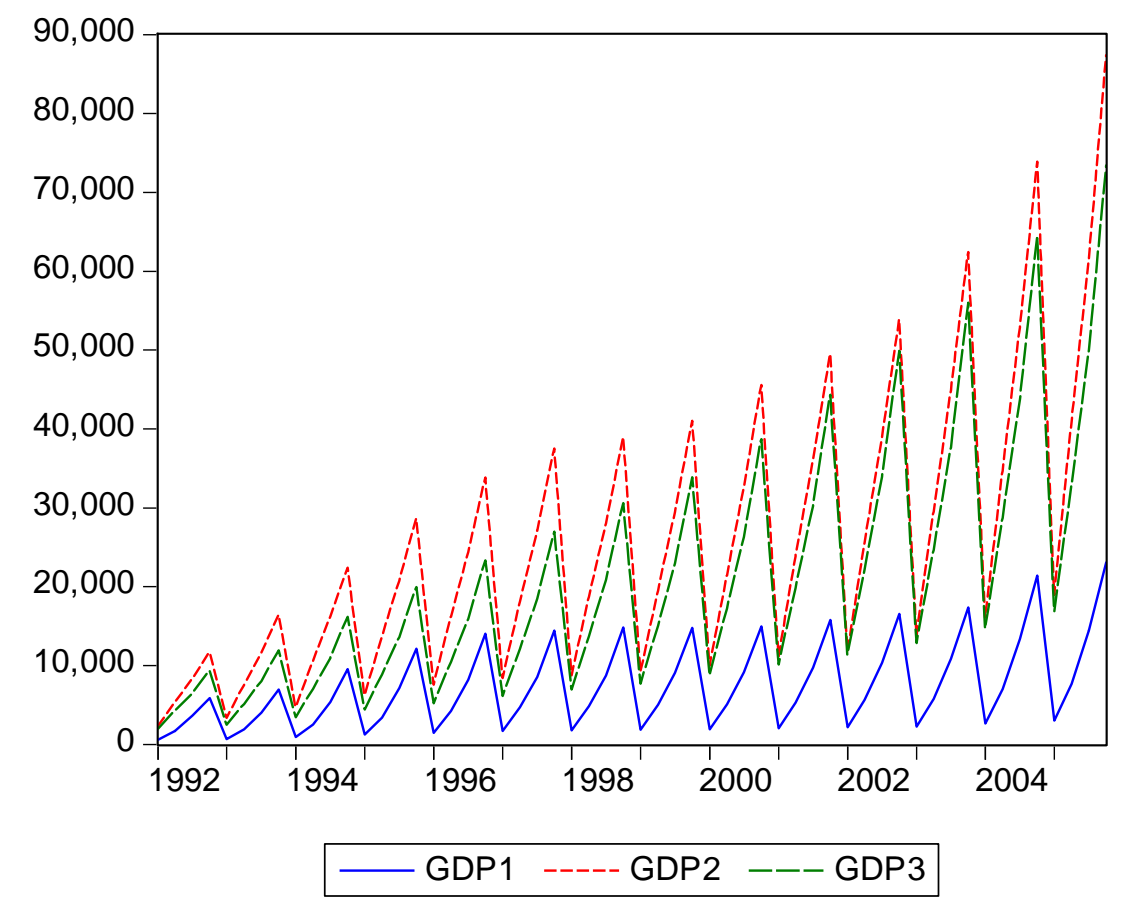

Figure 2: Quarterly GDP (cumulated) as the aggregate in current prices, 1992Q1-2005Q4, per industry (primary, secondary and tertiary) (the data are given in Appendix A) 


\section{LOG(GDP)-LOG(GDP(-1))-LOG(GDP(-4))+LOG(GDP(-5))}

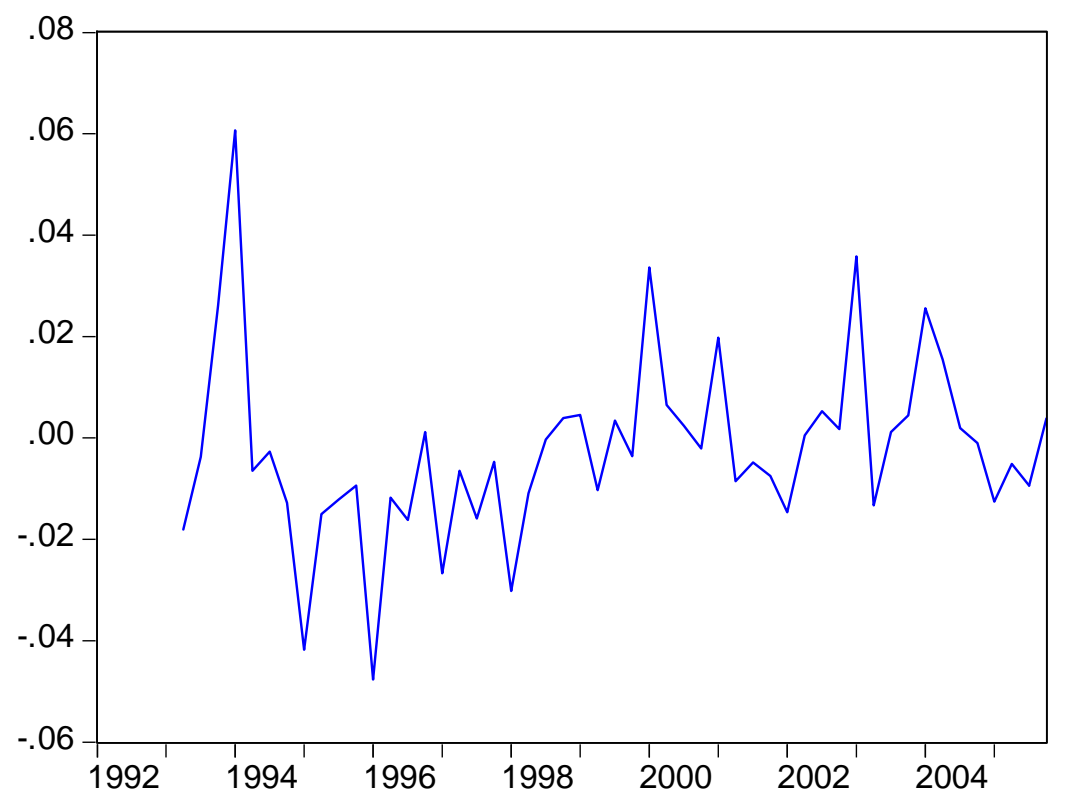

Figure 3: Quarterly change in the annual growth rate of GDP (cumulated) as the aggregate in current prices, 1992Q1-2005Q4 


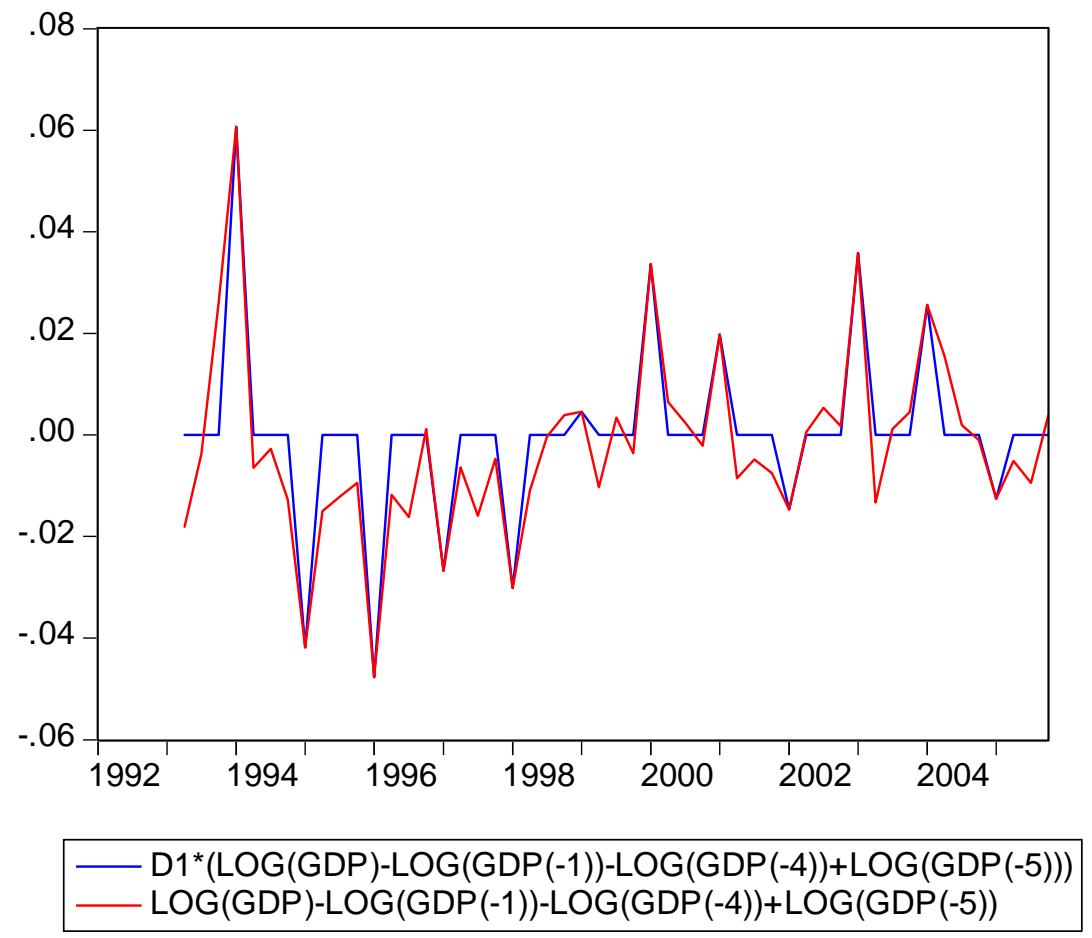

Figure 4: Quarterly change in the annual growth rate of GDP (cumulated) as the aggregate in current prices, 1992Q1-2005Q4 versus the same variable when assumed to be non-zero only in Quarter 1 


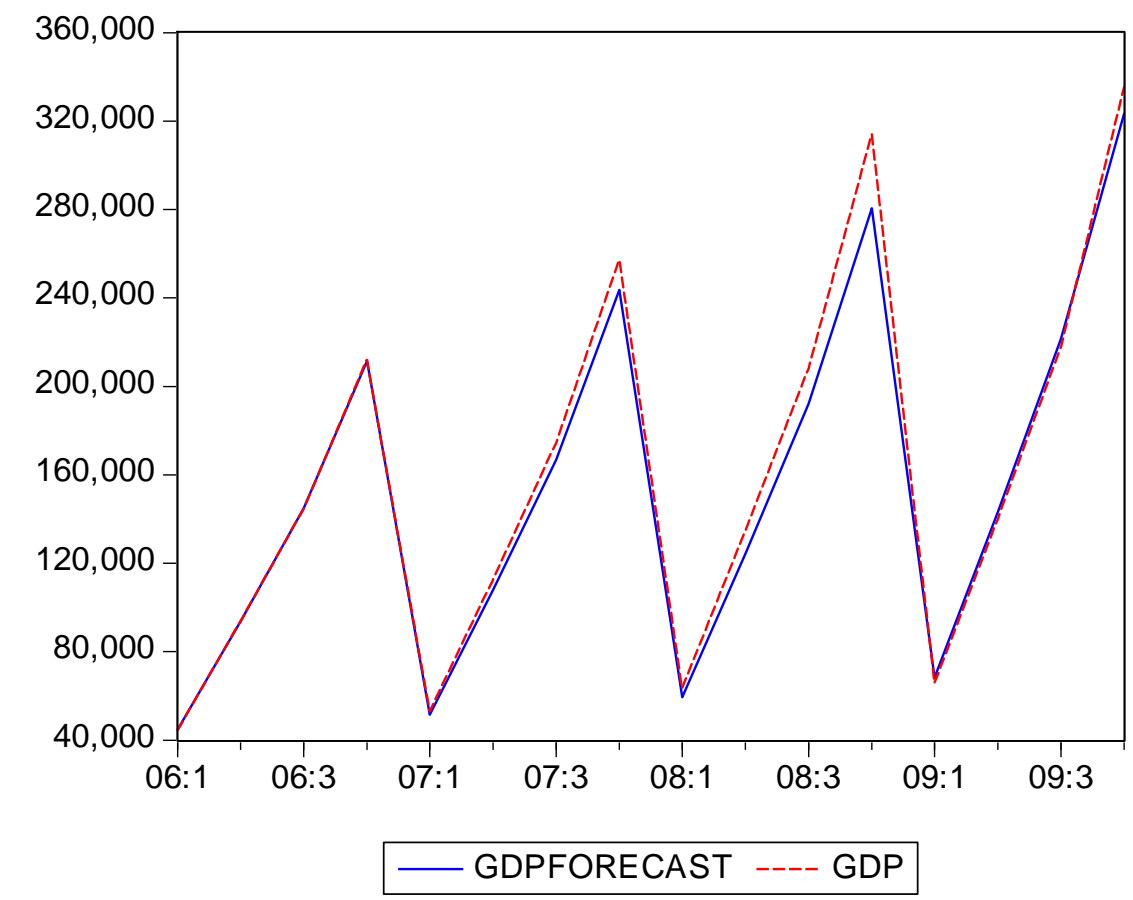

Figure 5: Multi-step-ahead forecasts (Dynamic Forecasts) for 2006Q1 to 2009Q4 from forecast origin 2005Q4 generated using (4). 


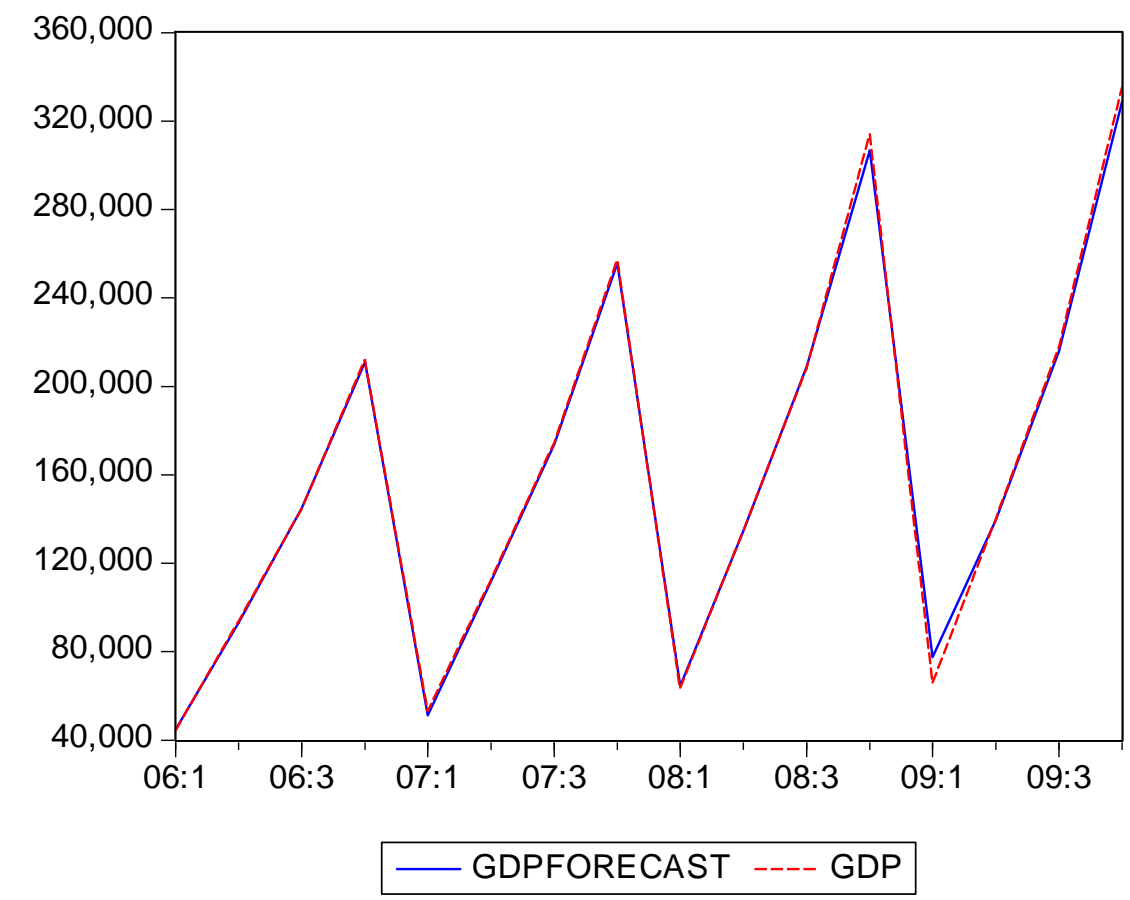

Figure 6: One-step-ahead forecasts (Static Forecasts) for 2006Q1 to 2009Q4 from forecast origin 2005Q4, 2006Q1, and so on, generated using (4). 


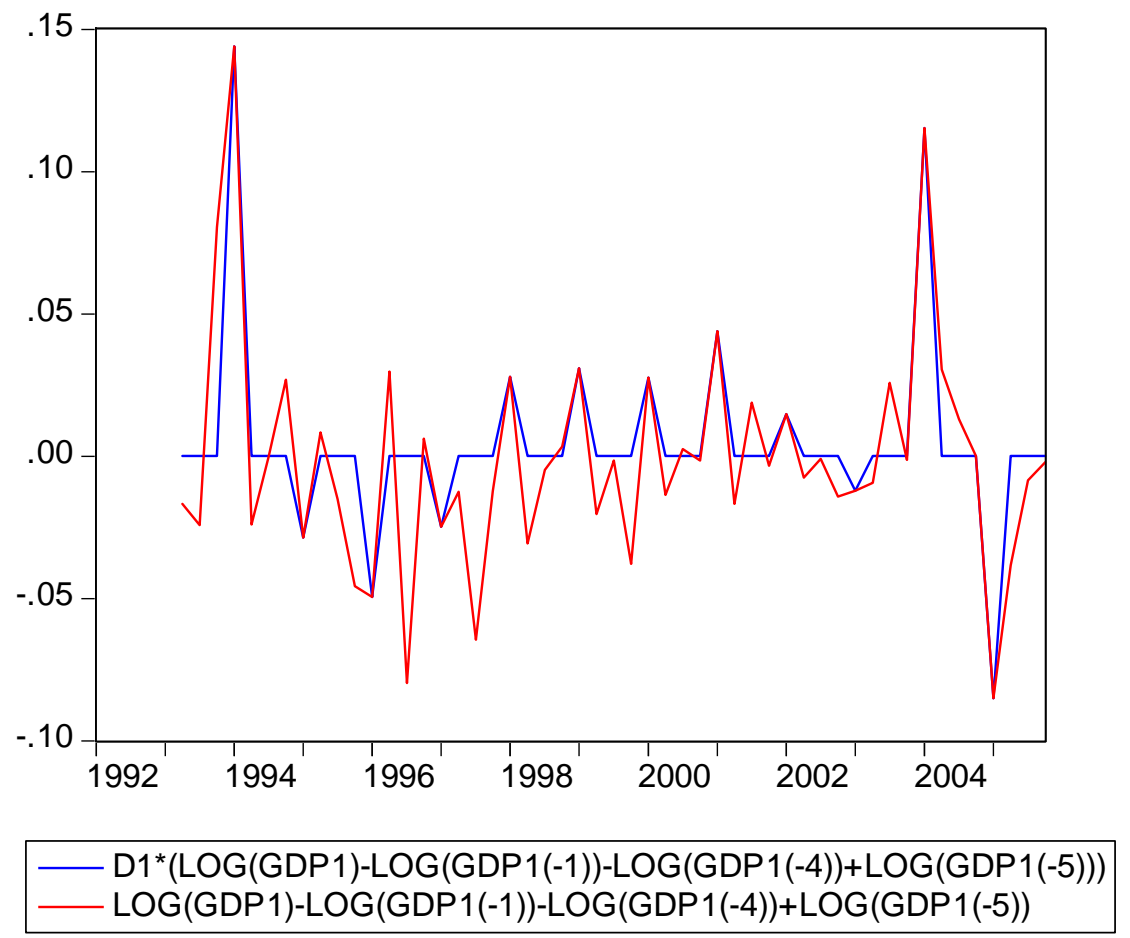

Figure 7: Quarterly change in the annual growth rate of GDP Primary Sector (cumulated) as the aggregate in current prices, 1992.1-2005.4 versus the same variable when assumed to be non-zero only in Quarter 1 


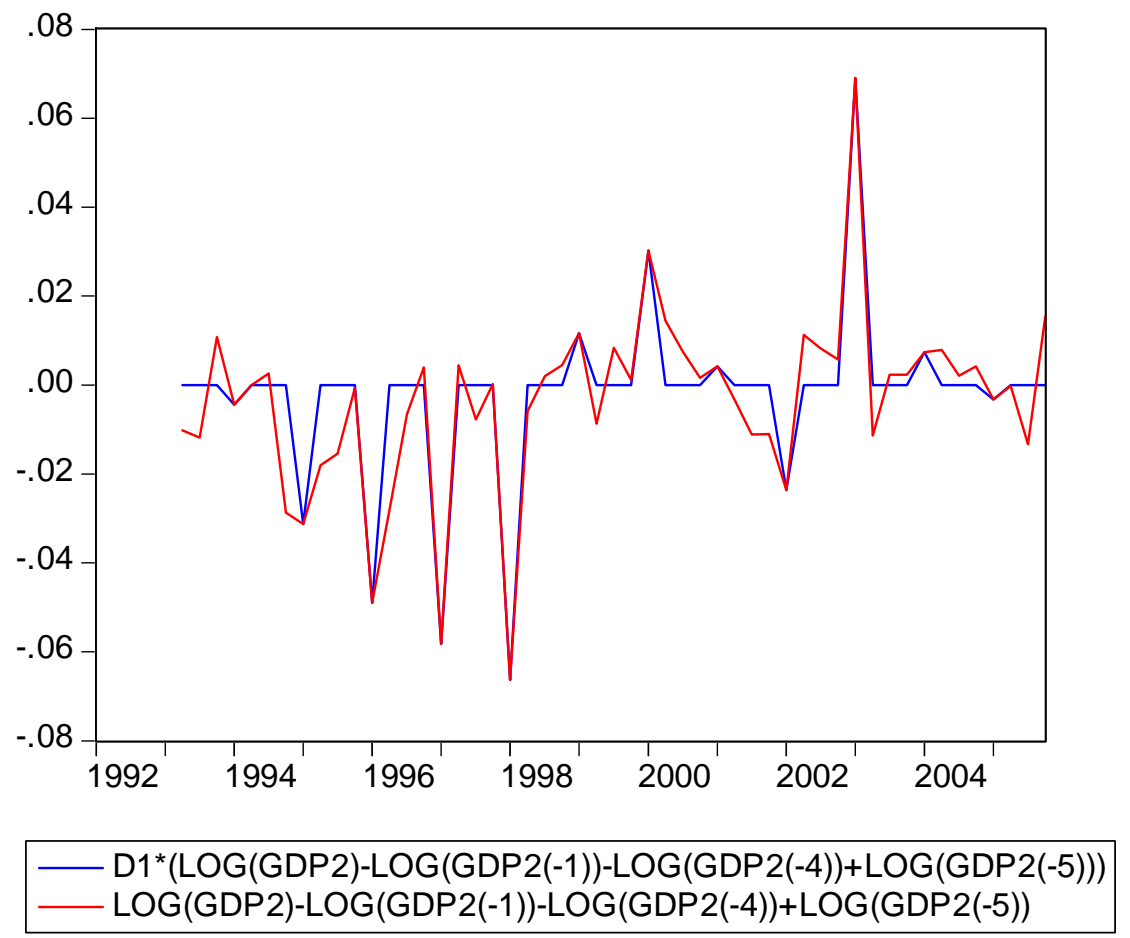

Figure 8: Quarterly change in the annual growth rate of GDP Secondary Sector (cumulated) as the aggregate in current prices, 1992.1-2005.4 versus the same variable when assumed to be non-zero only in Quarter 1 


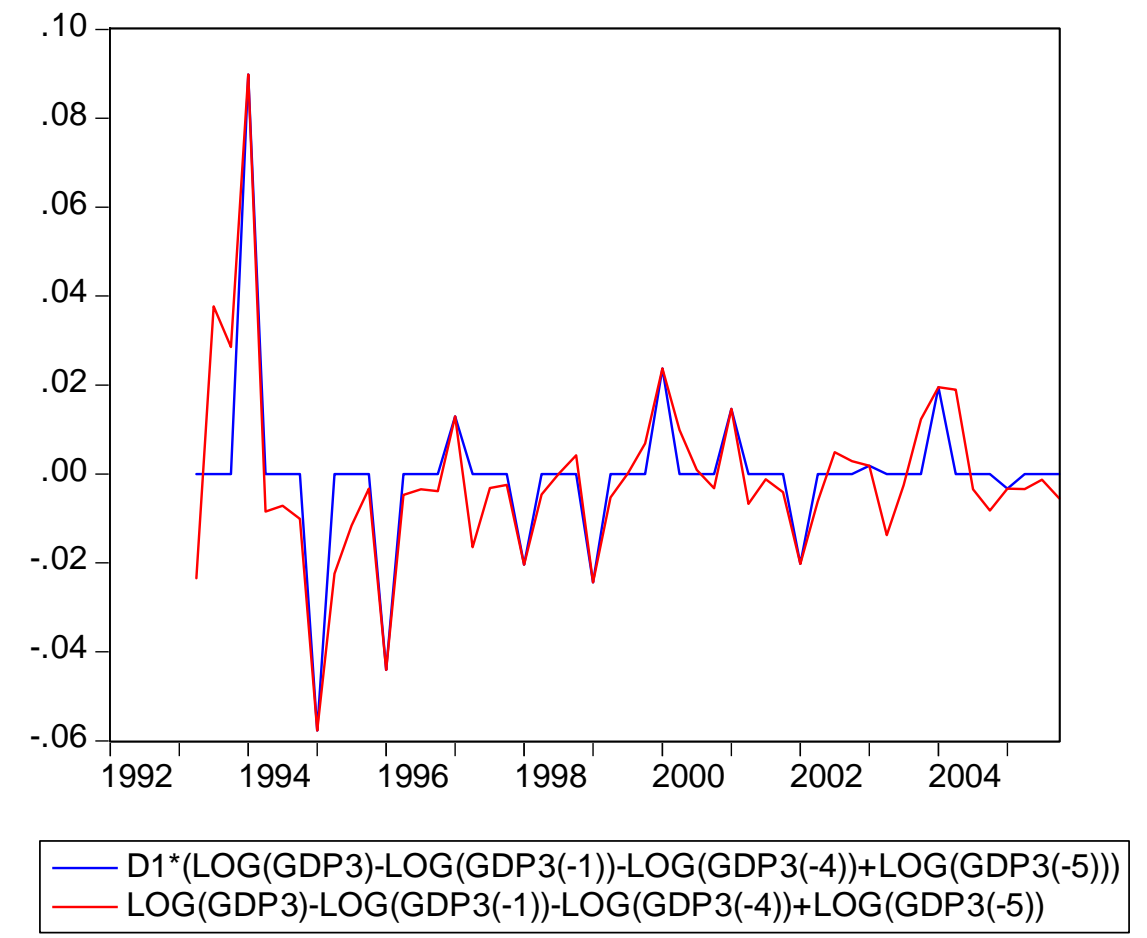

Figure 9: Quarterly change in the annual growth rate of GDP Tertiary Sector (cumulated) as the aggregate in current prices, 1992.1-2005.4 versus the same variable when assumed to be non-zero only in Quarter 1 


\section{GROWTH}

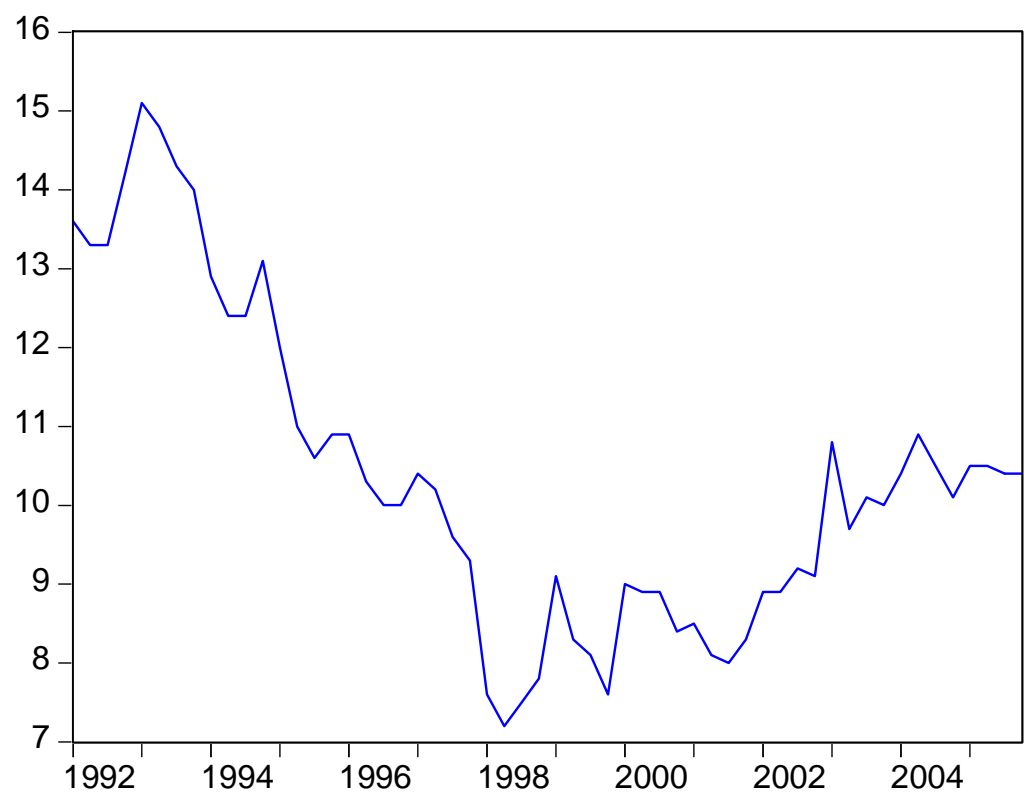

Figure 10: Growth Rate of total GDP, at constant prices, 1992Q1-2005Q4. 


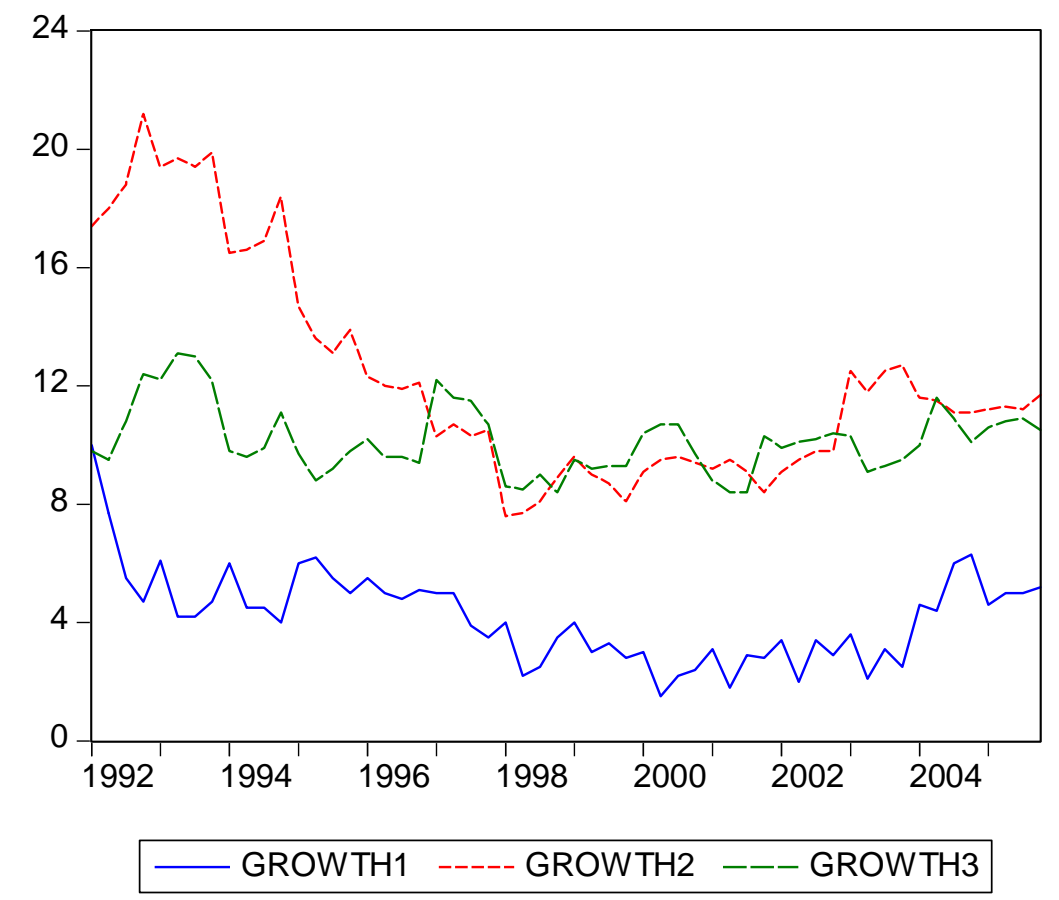

Figure 11: Growth Rate of GDP in the three sectors, at constant prices, 1992Q1-2005Q4. 


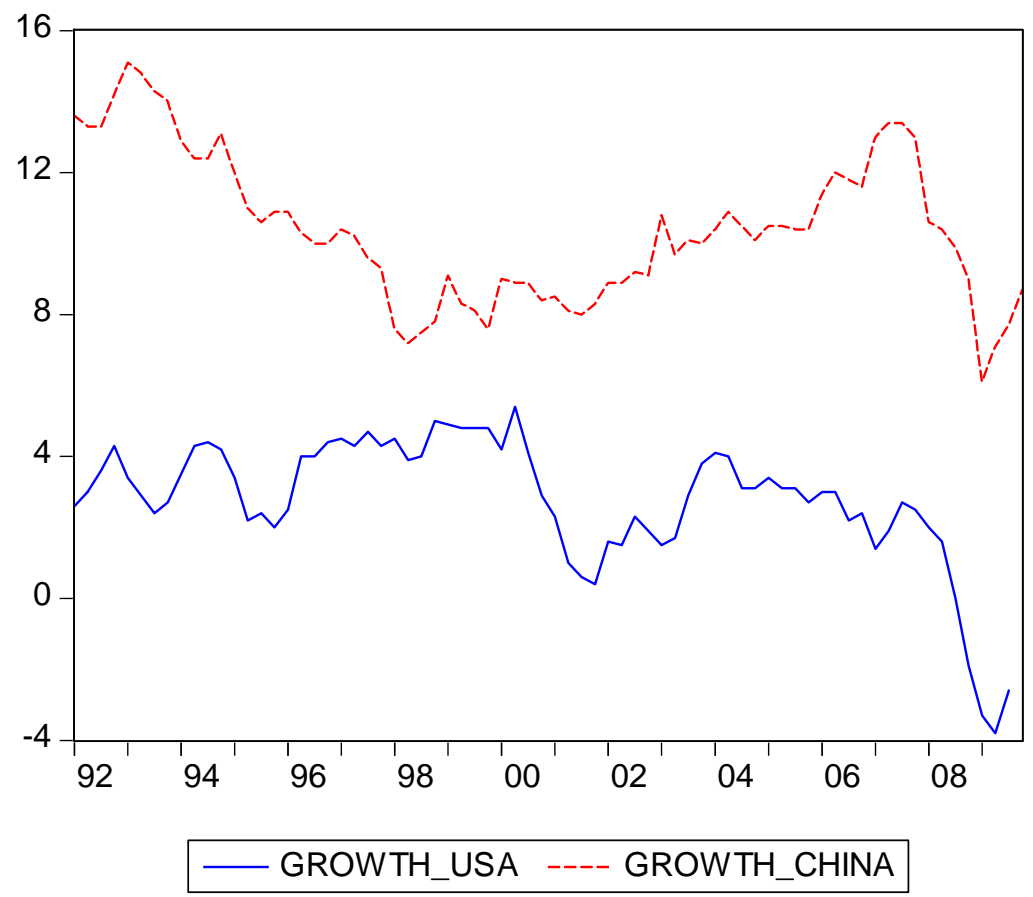

Figure 12: Real growth rates, USA and China, 1992Q1-2009Q4. 
Table 1: Multiple-step-ahead forecasts and realizations of the levels of current prices GDP, 2006Q1-2009Q4, percentage forecast error computed as $100 * \frac{G D P-\text { Forecast }}{G D P}$

$\begin{array}{cccc}\text { Quarter } & \text { Forecast } & \text { GDP } & \begin{array}{c}\text { Percentage } \\ \text { Forecast Error }\end{array} \\ \text { 2006Q1 } & 44702.33 & 44419.80 & -0.636 \\ \text { 2006Q2 } & 93691.30 & 93611.60 & -0.085 \\ \text { 2006Q3 } & 144968.4 & 144569.6 & -0.276 \\ \text { 2006Q4 } & 211573.2 & 211923.0 & 0.165 \\ \text { 2007Q1 } & 51466.36 & 53058.00 & 3.000 \\ \text { 2007Q2 } & 107868.0 & 112458.0 & 4.082 \\ \text { 2007Q3 } & 166903.9 & 174428.0 & 4.314 \\ \text { 2007Q4 } & 243586.9 & 257306.0 & 5.332 \\ \text { 2008Q1 } & 59286.41 & 63475.00 & 6.599 \\ \text { 2008Q2 } & 124257.9 & 134726.0 & 7.770 \\ \text { 2008Q3 } & 192264.1 & 208025.0 & 7.576 \\ \text { 2008Q4 } & 280598.7 & 314045.0 & 10.650 \\ \text { 2009Q1 } & 68332.17 & 65745.00 & -3.935 \\ \text { 2009Q2 } & 143216.9 & 139862.0 & -2.399 \\ \text { 2009Q3 } & 221599.3 & 217817.0 & -1.736 \\ \text { 2009Q4 } & 323411.7 & 335353.0 & 3.962\end{array}$


Table 2: One-step-ahead forecasts and realizations of the levels of current prices GDP, 2006Q1-2009Q4, percentage forecast error computed as $100 * \frac{G D P-\text { Forecast }}{G D P}$

$\begin{array}{rrrr}\text { Quarter } & & & \begin{array}{r}\text { Percentage } \\ \text { Forecast Error }\end{array} \\ \text { 2006Q1 } & \text { Forecast } & \text { GDP } & -0.636 \\ \text { 2006Q2 } & 93099.33 & 44419.80 & 0.547 \\ \text { 2006Q3 } & 144845.1 & 93611.60 & -0.191 \\ \text { 2006Q4 } & 210991.2 & 211956.6 & 0.440 \\ \text { 2007Q1 } & 51225.62 & 53058.00 & 3.454 \\ \text { 2007Q2 } & 111816.0 & 112458.0 & 0.571 \\ \text { 2007Q3 } & 173675.1 & 174428.0 & 0.432 \\ \text { 2007Q4 } & 255692.1 & 257306.0 & 0.627 \\ \text { 2008Q1 } & 64455.67 & 63475.00 & -1.545 \\ \text { 2008Q2 } & 134537.1 & 134726.0 & 0.140 \\ \text { 2008Q3 } & 208966.8 & 208025.0 & -0.453 \\ \text { 2008Q4 } & 306866.3 & 314045.0 & 2.286 \\ \text { 2009Q1 } & 77514.53 & 65745.00 & -17.902 \\ \text { 2009Q2 } & 139544.1 & 139862.0 & 0.227 \\ \text { 2009Q3 } & 215955.3 & 217817.0 & 0.855 \\ \text { 2009Q4 } & 328827.5 & 335353.0 & 1.984 \\ & & & \\ \text { Median error } & & & 0.436 \\ \text { Median } & & & 0.599\end{array}$


Table 3: Multiple-step-ahead forecasts and realizations of the levels of current prices GDP, Primary Sector, 2006Q1-2009Q4, percentage forecast error computed as $100 * \frac{G D P-\text { Forecast }}{G D P}$

$\begin{array}{lrrr}\text { Quarter } & \text { Forecast } & \text { GDP1 } & \begin{array}{r}\text { Percentage } \\ \text { Forecast Error }\end{array} \\ 2006: 1 & 3253.665 & 3093.000 & -5.195 \\ 2006: 2 & 8261.563 & 7973.600 & -3.612 \\ 2006: 3 & 15602.39 & 15058.20 & -3.614 \\ 2006: 4 & 24908.20 & 24040.00 & -3.612 \\ 2007: 1 & 3520.170 & 3654.000 & 3.663 \\ 2007: 2 & 8938.260 & 9283.000 & 3.714 \\ 2007: 3 & 16880.37 & 17937.00 & 5.891 \\ 2007: 4 & 26948.41 & 28627.00 & 5.864 \\ 2008: 1 & 3816.436 & 4720.000 & 19.143 \\ 2008: 2 & 9690.526 & 11800.00 & 17.877 \\ 2008: 3 & 18301.06 & 22062.00 & 17.047 \\ 2008: 4 & 29216.45 & 33702.00 & 13.309 \\ 2009: 1 & 4146.254 & 4700.000 & 11.782 \\ 2009: 2 & 10527.98 & 12025.00 & 12.449 \\ 2009: 3 & 19882.65 & 22500.00 & 11.633 \\ 2009: 4 & 31741.35 & 35477.00 & 11.769\end{array}$


Table 4: One-step-ahead forecasts and realizations of the levels of current prices GDP, Primary Sector, 2006Q1-2009Q4, percentage forecast error computed as

$$
100 * \frac{G D P-\text { Forecast }}{G D P}
$$

$\begin{array}{crrr}\text { obs } & \text { Forecast } & \text { GDP1 } & \begin{array}{r}\text { Percentage } \\ \text { Forecast Error }\end{array} \\ \text { 2006Q1 } & 3253.665 & 3093.000 & -5.194 \\ \text { 2006Q2 } & 7853.609 & 7973.600 & 1.505 \\ \text { 2006Q3 } & 15058.56 & 15058.20 & -0.002 \\ \text { 2006Q4 } & 24039.44 & 24040.00 & 0.002 \\ \text { 2007Q1 } & 3229.705 & 3654.000 & 11.612 \\ \text { 2007Q2 } & 9419.830 & 9283.000 & -1.474 \\ \text { 2007Q3 } & 17531.01 & 17937.00 & 2.263 \\ \text { 2007Q4 } & 28635.92 & 28627.00 & -0.032 \\ \text { 2008Q1 } & 4360.271 & 4720.000 & 7.621 \\ \text { 2008Q2 } & 11991.18 & 11800.00 & -1.620 \\ \text { 2008Q3 } & 22800.45 & 22062.00 & -3.347 \\ \text { 2008Q4 } & 35210.40 & 33702.00 & -4.476 \\ \text { 2009Q1 } & 5568.335 & 4700.000 & -18.475 \\ \text { 2009Q2 } & 11750.00 & 12025.00 & 2.287 \\ \text { 2009Q3 } & 22482.67 & 22500.00 & 0.077 \\ \text { 2009Q4 } & 34371.09 & 35477.00 & 3.218 \\ & & & \\ \text { Median } & & & \\ \text { error } & & & \\ \text { Median } & & & \\ \text { absolute } & & & \\ \text { error } & & & \end{array}$


Table 5: Multiple-step-ahead forecasts and realizations of the levels of current prices GDP, Secondary Sector, 2006Q1-2009Q4, percentage forecast error computed as $100 * \frac{G D P-\text { Forecast }}{G D P}$

$\begin{array}{rrrr}\text { Quarter } & \text { Forecast } & \text { GDP2 } & \begin{array}{r}\text { Percentage } \\ \text { Forecast Error }\end{array} \\ \text { 2006Q1 } & 22439.63 & 22076.10 & -1.647 \\ \text { 2006Q2 } & 48387.80 & 47909.40 & -0.999 \\ \text { 2006Q3 } & 72804.70 & 72008.20 & -1.106 \\ \text { 2006Q4 } & 103352.4 & 103162.0 & -0.185 \\ \text { 2007Q1 } & 26565.62 & 26465.00 & -0.380 \\ \text { 2007Q2 } & 57284.89 & 57614.00 & 0.571 \\ \text { 2007Q3 } & 86191.34 & 86405.00 & 0.247 \\ \text { 2007Q4 } & 122355.8 & 124799.0 & 1.958 \\ \text { 2008Q1 } & 31473.37 & 31658.00 & 0.583 \\ \text { 2008Q2 } & 67867.76 & 69330.00 & 2.109 \\ \text { 2008Q3 } & 102114.4 & 103974.0 & 1.789 \\ \text { 2008Q4 } & 144960.0 & 149003.0 & 2.713 \\ \text { 2009Q1 } & 37315.21 & 31968.00 & -16.727 \\ \text { 2009Q2 } & 80464.83 & 70070.00 & -14.835 \\ \text { 2009Q3 } & 121068.1 & 106477.0 & -13.704 \\ \text { 2009Q4 } & 171866.3 & 156958.0 & -8.674\end{array}$


Table 6: One-step-ahead forecasts and realizations of the levels of current prices GDP, Secondary Sector, 2006Q1-2009Q4, percentage forecast error computed as $100 * \frac{G D P-\text { Forecast }}{G D P}$

$\begin{array}{crrr}\text { Quarter } & \text { Forecast } & \text { GDP2 } & \begin{array}{r}\text { Percentage } \\ \text { Forecast Error }\end{array} \\ \text { 2006Q1 } & 22439.63 & 22076.10 & -1.647 \\ \text { 2006Q2 } & 47603.90 & 47909.40 & 0.638 \\ \text { 2006Q3 } & 72084.89 & 72008.20 & -0.107 \\ \text { 2006Q4 } & 102221.7 & 103162.0 & 0.911 \\ \text { 2007Q1 } & 26087.10 & 26465.00 & 1.428 \\ \text { 2007Q2 } & 57434.16 & 57614.00 & 0.312 \\ \text { 2007Q3 } & 86594.29 & 86405.00 & -0.219 \\ \text { 2007Q4 } & 123787.5 & 124799.0 & 0.811 \\ \text { 2008Q1 } & 32039.26 & 31658.00 & -1.204 \\ \text { 2008Q2 } & 68919.10 & 69330.00 & 0.593 \\ \text { 2008Q3 } & 103975.7 & 103974.0 & -0.002 \\ \text { 2008Q4 } & 150174.8 & 149003.0 & -0.786 \\ \text { 2009Q1 } & 37825.67 & 31968.00 & -18.324 \\ \text { 2009Q2 } & 70008.89 & 70070.00 & 0.087 \\ \text { 2009Q3 } & 105083.8 & 106477.0 & 1.308 \\ \text { 2009Q4 } & 152590.0 & 156958.0 & 2.863 \\ & & & \\ \text { Median } & & & \\ \text { error } & & & \\ \text { Median } & & & \\ \text { absolute } & & & \\ \text { error } & & & \end{array}$


Table 7: Multiple-step-ahead forecasts and realizations of the levels of current prices GDP, Tertiary Sector, 2006Q1-2009Q4, percentage forecast error computed as $100 * \frac{G D P-\text { Forecast }}{G D P}$

$\begin{array}{rrrr}\text { Quarter } & \text { Forecast } & \text { GDP3 } & \begin{array}{r}\text { Percentage } \\ \text { Forecast Error }\end{array} \\ \text { 2006Q1 } & 19197.17 & 19250.70 & 0.278 \\ \text { 2006Q2 } & 37409.47 & 37728.60 & 0.846 \\ \text { 2006Q3 } & 56898.92 & 57503.20 & 1.051 \\ \text { 2006Q4 } & 83579.60 & 84721.00 & 1.347 \\ \text { 2007Q1 } & 21864.42 & 22939.00 & 4.685 \\ \text { 2007Q2 } & 42607.14 & 45561.00 & 6.483 \\ \text { 2007Q3 } & 64804.45 & 70086.00 & 7.536 \\ \text { 2007Q4 } & 95192.14 & 103880.0 & 8.364 \\ \text { 2008Q1 } & 24918.96 & 27097.00 & 8.038 \\ \text { 2008Q2 } & 48559.52 & 53596.00 & 9.397 \\ \text { 2008Q3 } & 73857.88 & 81989.00 & 9.917 \\ \text { 2008Q4 } & 108490.8 & 131340.0 & 17.397 \\ \text { 2009Q1 } & 28419.28 & 29077.00 & 2.262 \\ \text { 2009Q2 } & 55380.59 & 57767.00 & 4.131 \\ \text { 2009Q3 } & 84232.57 & 88840.00 & 5.186 \\ \text { 2009Q4 } & 123730.4 & 142918.0 & 15.508\end{array}$


Table 8: One-step-ahead forecasts and realizations of the levels of current prices GDP, Tertiary Sector, 2006Q1-2009Q4, percentage forecast error computed as

$$
100 * \frac{G D P-\text { Forecast }}{G D P}
$$

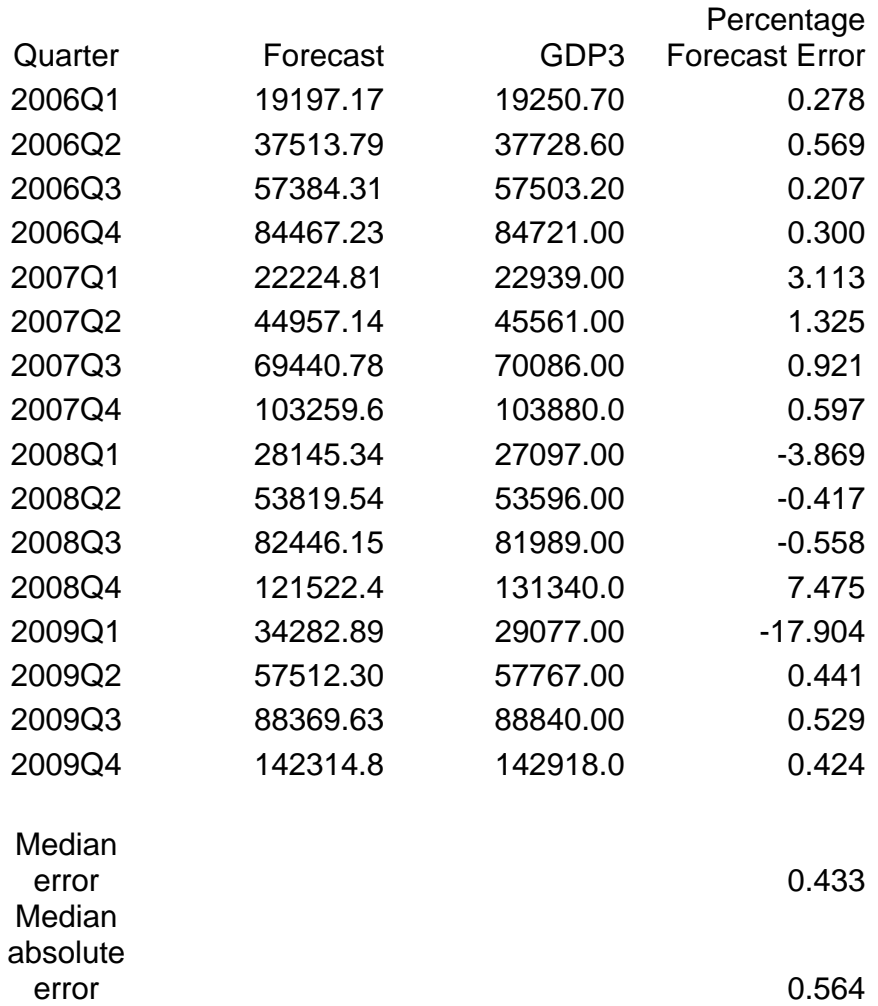


Table 9: One-step-ahead forecast for constant prices growth in GDP (total, based on cumulated data), realizations and differences calculated as Realization-Forecast

$\begin{array}{crrr}\text { Quarter } & \text { Forecast } & \text { GROWTH } & \begin{array}{r}\text { Growth- } \\ \text { Forecast }\end{array} \\ \text { 2006Q1 } & 10.7 & 11.4 & 0.7 \\ \text { 2006Q2 } & 11.0 & 12.0 & 1.0 \\ \text { 2006Q3 } & 12.0 & 11.8 & -0.2 \\ \text { 2006Q4 } & 11.8 & 11.6 & -0.2 \\ \text { 2007Q1 } & 11.9 & 13.0 & 1.1 \\ \text { 2007Q2 } & 12.6 & 13.4 & 0.8 \\ \text { 2007Q3 } & 13.4 & 13.4 & 0.0 \\ \text { 2007Q4 } & 13.4 & 13.0 & -0.4 \\ \text { 2008Q1 } & 13.3 & 10.6 & -2.7 \\ \text { 2008Q2 } & 10.2 & 10.4 & 0.2 \\ \text { 2008Q3 } & 10.4 & 9.90 & -0.5 \\ \text { 2008Q4 } & 9.90 & 9.00 & -0.9 \\ \text { 2009Q1 } & 9.30 & 6.10 & -3.2 \\ \text { 2009Q2 } & 5.73 & 7.10 & 1.4 \\ \text { 2009Q3 } & 7.10 & 7.70 & 0.6 \\ \text { 2009Q4 } & 7.70 & 8.70 & 1.0 \\ & & & \\ \text { Median } & & & \\ \text { error } & & & \\ \text { Median } & & & \\ \text { absolute } & & & \\ \text { error } & & & \end{array}$


Table 10: One-step-ahead forecast for constant prices growth in GDP (Primary Sector, based on cumulated data), realizations and differences calculated as Realization-Forecast

\begin{tabular}{|c|c|c|c|}
\hline Quarter & Forecast & GROWTH1 & $\begin{array}{l}\text { Growth1- } \\
\text { Forecast- }\end{array}$ \\
\hline 2006Q1 & 5.9 & 4.5 & -1.4 \\
\hline 2006Q2 & 3.5 & 5.1 & 1.6 \\
\hline 2006Q3 & 5.1 & 4.9 & -0.2 \\
\hline 2006Q4 & 4.9 & 5.0 & 0.1 \\
\hline 2007Q1 & 5.7 & 4.4 & -1.3 \\
\hline 2007Q2 & 3.4 & 4.0 & 0.6 \\
\hline 2007Q3 & 4.0 & 4.3 & 0.3 \\
\hline 2007Q4 & 4.3 & 3.7 & -0.6 \\
\hline 2008Q1 & 4.4 & 2.8 & -1.6 \\
\hline 2008Q2 & 1.8 & 3.5 & 1.7 \\
\hline 2008Q3 & 3.5 & 4.5 & 1.0 \\
\hline 2008Q4 & 4.5 & 5.5 & 1.0 \\
\hline 2009Q1 & 6.2 & 3.5 & -2.7 \\
\hline 2009Q2 & 2.5 & 3.8 & 1.3 \\
\hline 2009Q3 & 3.8 & 4.0 & 0.2 \\
\hline 2009Q4 & 4.0 & 4.2 & 0.2 \\
\hline \multicolumn{3}{|l|}{ Median } & 0.20 \\
\hline \multicolumn{4}{|l|}{ Median } \\
\hline error & & & 1.00 \\
\hline
\end{tabular}


Table 11: One-step-ahead forecast for constant prices growth in GDP (Secondary Sector, based on cumulated data), realizations and differences calculated as Realization-Forecast

\begin{tabular}{|c|c|c|c|}
\hline Quarter & Forecast & GROWTH2 & $\begin{array}{l}\text { Growth2- } \\
\text { Forecast- }\end{array}$ \\
\hline 2006Q1 & 10.8 & 12.6 & 1.8 \\
\hline 2006Q2 & 12.6 & 13.6 & 1.0 \\
\hline 2006Q3 & 13.6 & 13.3 & -0.3 \\
\hline 2006Q4 & 13.3 & 13.0 & -0.3 \\
\hline 2007Q1 & 12.1 & 14.6 & 2.5 \\
\hline 2007Q2 & 14.6 & 15.0 & 0.4 \\
\hline 2007Q3 & 15.0 & 14.8 & -0.2 \\
\hline 2007Q4 & 14.8 & 14.7 & -0.1 \\
\hline 2008Q1 & 13.8 & 11.5 & -2.3 \\
\hline 2008Q2 & 11.5 & 11.3 & -0.2 \\
\hline 2008Q3 & 11.3 & 10.6 & -0.7 \\
\hline 2008Q4 & 10.6 & 9.3 & -1.3 \\
\hline 2009Q1 & 8.4 & 5.3 & -3.1 \\
\hline 2009Q2 & 5.3 & 6.6 & 1.3 \\
\hline 2009Q3 & 6.6 & 7.5 & 0.9 \\
\hline 2009Q4 & 7.5 & 9.5 & 2.0 \\
\hline $\begin{array}{l}\text { Median } \\
\text { error } \\
\text { Median } \\
\text { absolute }\end{array}$ & & & -0.15 \\
\hline error & & & 0.95 \\
\hline
\end{tabular}


Table 12: One-step-ahead forecast for constant prices growth in GDP (Tertiary Sector, based on cumulated data), realizations and differences calculated as Realization-Forecast

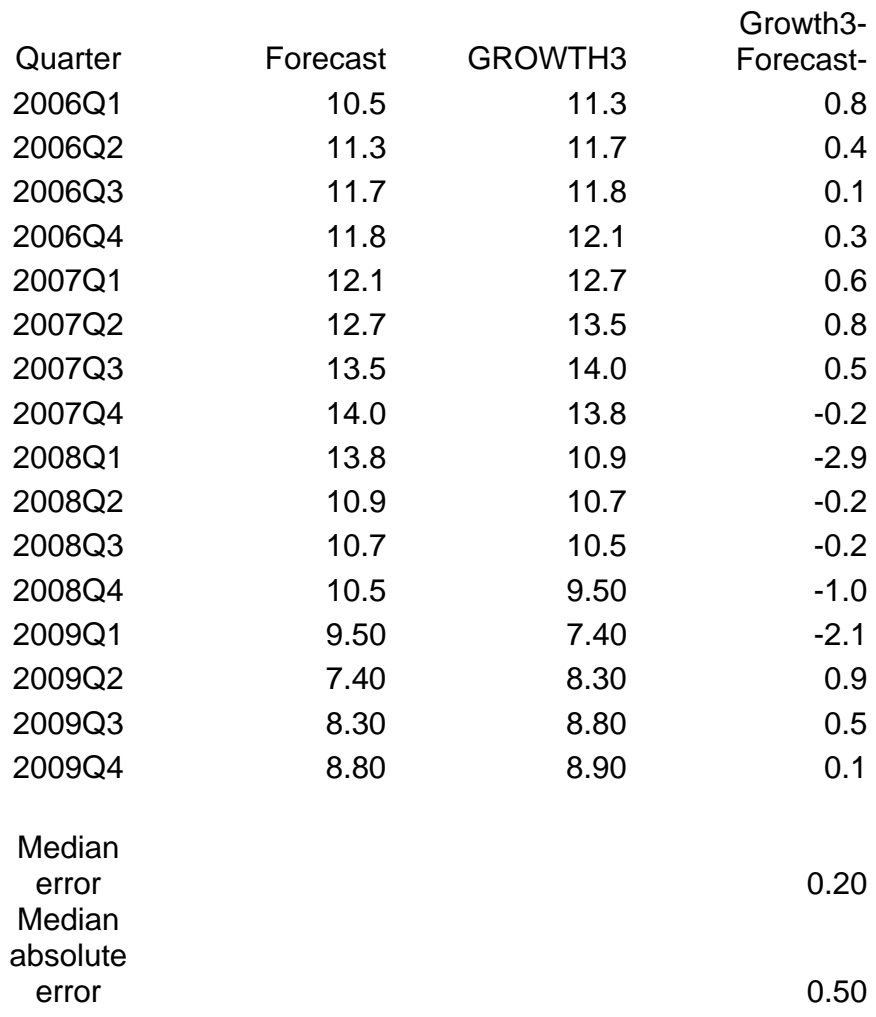




\section{References}

Dong, Lihua (2006), Quarterly GDP Estimation in China, in Series 9 of "Research of Methodological Issues in National Accounts - China”, OECD

http://www.oecd.org/document/57/0,3343,en_2649_34253_31640185_1_1_1_1,00.html

Franses, Philip Hans (1998), Time Series Models for Business and Economic Forecasting, Cambridge: Cambridge University Press.

National Bureau of Statistics of China (2007), China Quarterly GDP Time Series, 19922005, Department of National Accounts, China Statistics Press, ISBN 978-7-5037-5356-5. 